\title{
Pushing the edge of dermoscopy in new directions: entomodermoscopy of Trombicula autumnalis
}

\author{
Nicola di Meo ${ }^{1}$, Mattia Fadel ${ }^{1 凶}$, Giusto Trevisan ${ }^{1}$
}

\begin{abstract}
Dermatologists are often faced with the challenge of patients presenting with nonspecific symptoms such as itching and/or erythema. These symptoms may be attributed to a number of diseases, many of which are trivial, and others even life-threatening. In order to establish the correct diagnosis, dermatologists must rely on good diagnostic tools and knowledge. Dermoscopy was introduced mainly for inspection of pigmented lesions, but its use has now also spread to non-melanoma skin cancer, inflammatory diseases, and almost any skin disease. This diagnostic technique also applies to skin infestation today, often offering the opportunity to rapidly identify new hidden features of parasites. This case report describes an unusual but representative case in which entomodermoscopy enabled a rapid diagnosis in a patient with a nonspecific erythematous patch. Whereas differential diagnosis of such skin manifestations could have been too laborious and misleading, dermoscopy easily allowed us to find a small parasite, later identified as Trombicula autumnalis.
\end{abstract}

Keywords: dermoscopy, chigger, Trombicula, entomodermoscopy, mite, ectoparasitic disease

Received: 10 February 2017 | Returned for modification: 16 February 2017 | Accepted: 9 March 2017

\section{Case report}

In October 2016, a 49-year-old man came to our hospital because of intense pruritic erythematous patches on the lower right leg (Fig. 1). The patient was otherwise in good health. He reported that itching had started the day before while he was waiting in an office. On the same day, he also took a walk in a park in the city. Upon a first general inspection, nothing peculiar was detected. A thorough inspection of the lesions with the aid of a dermatoscope made it possible to find a parasite with a strong fluorescent orange color (Fig. 2). The parasite was less than $0.5 \mathrm{~mm}$ long with some legs and a longitudinal white stripe. No other parasites were found on the patient. The parasite was photographed, removed without local anesthetic, and analyzed under a microscope with 40× magnification. Although recognition was not immediate because the mite was traumatized, with its head detached and lateralized, it was still possible to identify six legs and larval stage features of Trombicula autumnalis (Fig. 3). This is the first report

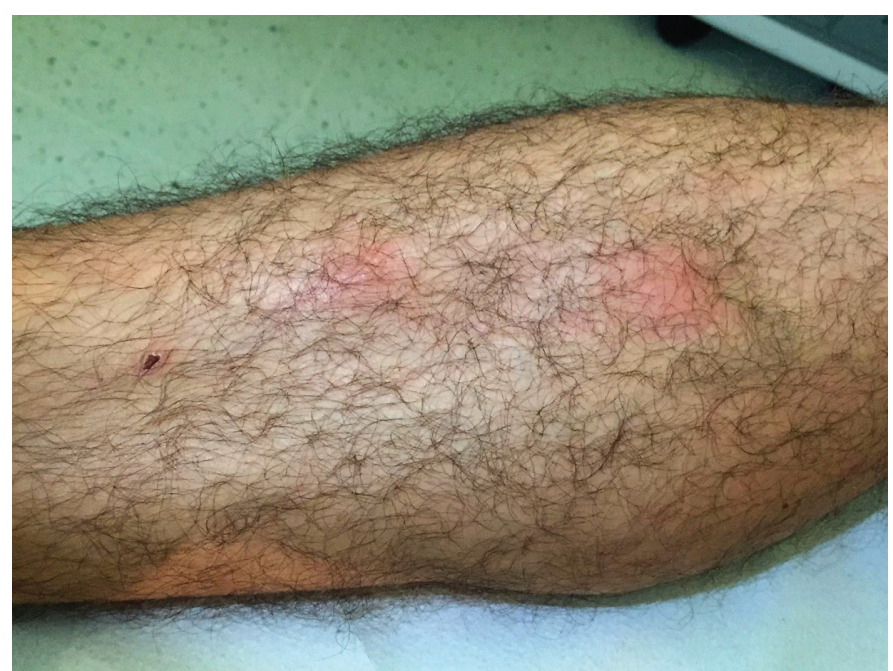

Figure 1 | Clinical presentation of the lower right leg with itchy red plaques. of this parasite in northern Italy. Interestingly, our patient denied having been in the countryside or in the woods. We can therefore assume that the infestation occurred in the city.

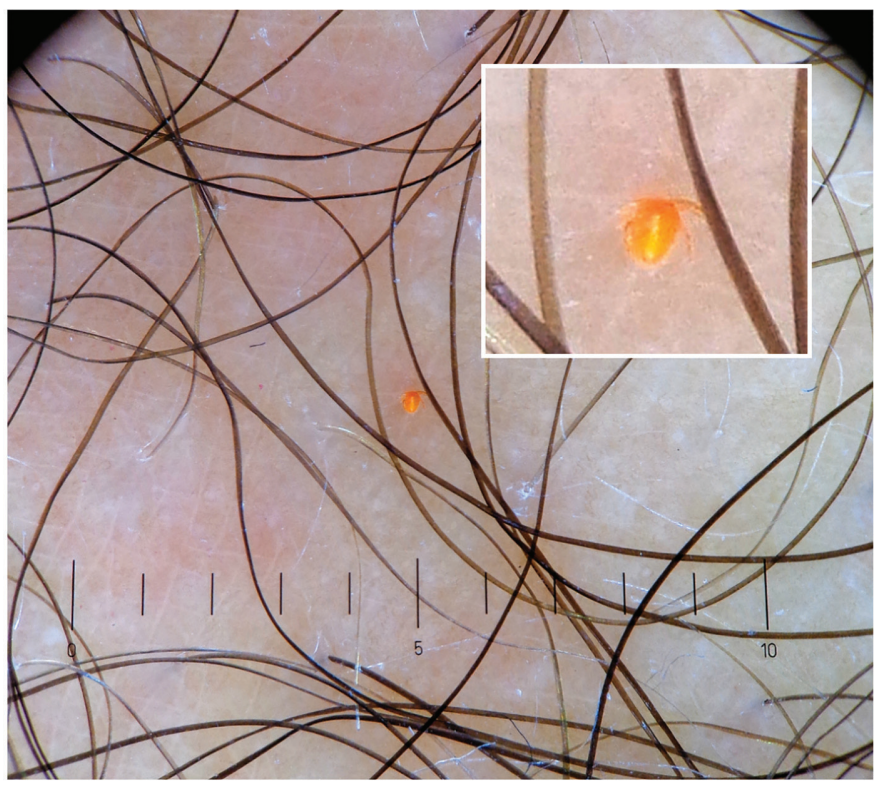

Figure 2 | Dermoscopy of Trombicula autumnalis, 10× magnification.

Trombicula autumnalis belongs to the class Arachnida, family Trombiculidae. These mites are also known in English-speaking countries as harvest mites, chiggers, berry bugs, red bugs, or scrub-itch mites, and as Erntemilbe, Herbstgrasmilbe, or Heumilbe in German-speaking countries (3). Mite larvae are most active from May to October (4). They hatch in 10 days from eggs laid in the ground, and then they climb on blades of grass or branches, where they are frequently found in clumps. The larval stage is approximately $0.25 \mathrm{~mm}$ long; its color can vary from white to orange or bright red and it typically has six legs (5). The larval stage is the only stage infesting warm-blooded vertebrates, including 


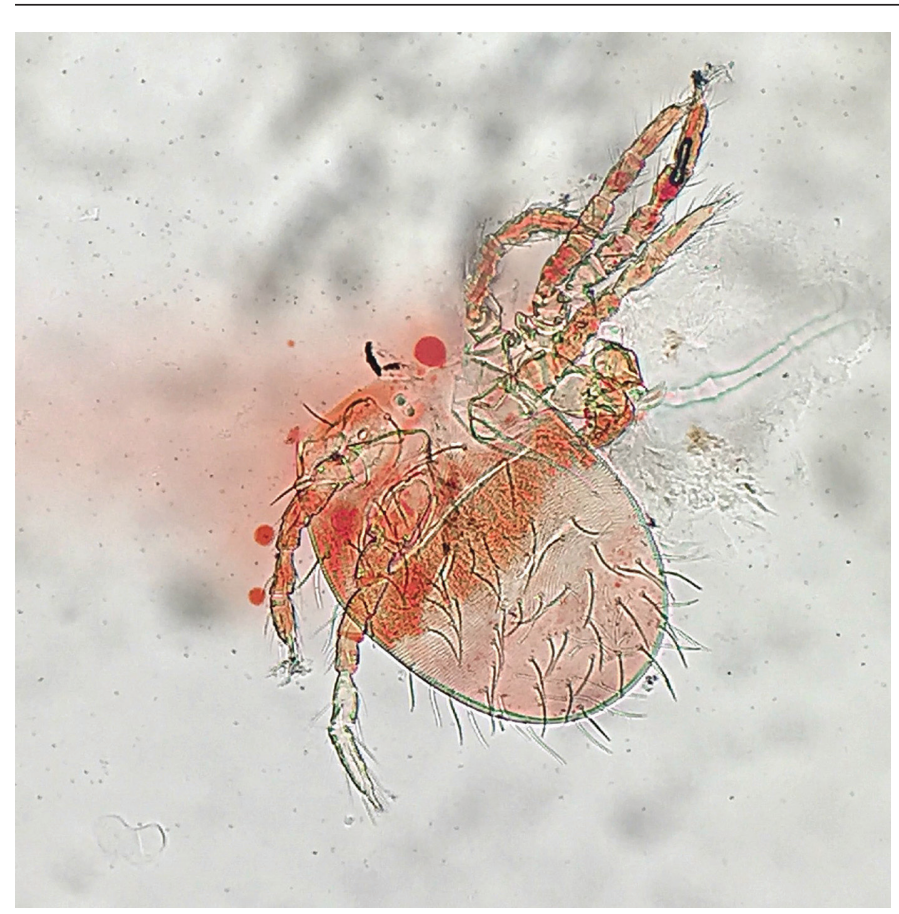

Figure 3| Microscopy of Trombicula autumnalis, 40× magnification.

human. For humans, contact with the mite usually occurs by walking through low vegetation or grass. Therefore, lesions are often found on the legs and ankles, especially on thinner skin. Because children frequently play on the ground, they can present with lesions anywhere on the skin. The larva attaches to the skin with its mouth, injects keratolytic substances into the skin, and feeds itself with the resulting "cellular soup" (5). The host response is largely caused by sensitization to the injected saliva. The intensity of the response may vary, ranging from a slightly irritable red erythema to wheals with papules or papulovesicles matched with intense itch arising between 3 and $6 \mathrm{~h}$ after exposure, with a peak after 12 to $24 \mathrm{~h}$. In extreme cases, regional adenitis may occur (6). The larvae feed for roughly 2 to 5 days to a maximum of 10 days. Afterwards, they fall onto the ground, where they turn into eightlegged nymphs and enter a quiescent phase until they become adults. The adult and nymph mites are soil-dwelling predators, which nourish themselves only on other arthropods and their eggs, and they are harmless to humans.

Although the infestation is self-limiting, a careful search for any remaining mites on the skin and thorough cleaning are advis- able. Symptomatic treatments with oral antihistamines and topical steroids quickly provide relief to the patient, which was also the case for our patient. Topical pesticides such as benzyl benzoate or permethrin may be used in extensive and severe infestations to ensure prompt eradication of the parasite (7). Washing clothes at $55{ }^{\circ} \mathrm{C}$ minimum is also important. Because the infestation derives from contact with soil or vegetation, wearing protective clothing, using insect repellents on trouser legs, and avoiding wearing wet socks and walking through tall grass are among the most recommended preventive measures (6).

\section{Discussion}

Trombiculiasis is rarely reported in current medical literature. There have been reports in Germany, the United Kingdom, and Spain (for Neotrombicula inopinata), and veterinary reports in southern Europe, but at the moment determining the spread of this parasite proves to be impossible $(3,6,8,9)$. The reason for this state of affairs may be the underestimation of the phenomenon, which is probably misdiagnosed and rarely brought to the attention of dermatologists. However, the role of Trombicula autumnalis as a possible vector is still unclear. For instance, in the South Pacific, Oceania, and Asia trombiculid mites of the genus Leptotrombidium are known to be vectors of tsutsugamushi, also known as scrub typhus. Furthermore, studies suggest that chiggers can carry the spirochete Borrelia burgdorferi, the etiologic agent of Lyme disease $(10,11)$. Trombicula autumnalis is also believed to be a possible carrier of Anaplasma phagocytophilum (formerly Ehrlichia phagocytophila), which causes human granulocytic anaplasmosis (12). These infections are difficult to diagnose and can cause significant morbidity and trigger several diseases (13). Late onset of disease is not to be underestimated because it may conceal the association between the infestation and the disease.

The key to avoiding misdiagnosis and saving time is to take advantage of dermoscopy and be prepared. Compared to other dermatological techniques or diagnostic tools such as biopsy, videodermatoscopy (14), or confocal laser scanning microscopy, dermoscopy is particularly fast, non-invasive, and cost-effective. In our case, it allowed us to quickly identify the parasite and to prescribe the most suitable treatment. Numerous cases of ectoparasitosis might be identified through dermoscopy, thus contributing to determining the spread of this pest.

\section{References}

1. di Meo N, Damiani G, Fadel M, Petrou S, Trevisan G. Cover Image: Dermoscopy of Ixodes scapularis on the scalp: feeding, engorgement and excrements. Br J Dermatol. 2016;174:1423.

2. Zalaudek I, Giacomel J, Cabo H, Di Stefani A, Ferrara G, Hofmann-Wellenhof R, et al. Entodermoscopy: a new tool for diagnosing skin infections and infestations. Dermatology. 2008;216:14-23.

3. Lewerenz V, Stege H, Hengge UR, Homey B, Bruch-Gerharz D. [Trombiculiasis in humans]. Hautarzt. 2008;59:771-4.

4. Elton C, Keay G. The seasonal occurrence of harvest mites (Trombicula autumnalis Shaw) on voles and mice near Oxford. Parasitology. 1936;28:110-4.

5. Diaz JH. Mites, including chiggers. In: Bennett JE, Dolin R, Blaser MJ, editors. Mandell, Douglas, and Bennett's principles and practice of infectious diseases. 8th ed. Philadelphia: Elsevier Saunders; 2015. p. 3260-5.

6. Yates VM. Harvest mites-a present from the Lake District. Clin Exp Dermatol. 1991;16:277-8.

7. Brown M, Hebert AA. Insect repellents: an overview. J Am Acad Dermatol. 1997; 36:243-9.

8. Stekolnikov AA, Santibáñez P, Palomar AM, Oteo JA. Neotrombicula inopinata (Acari: Trombiculidae)-a possible causative agent of trombiculiasis in Europe. Parasit Vectors. 2014;7:90.

9. Giannoulopoulos GD, Desilla LJ, Desilla ES, Papadopoulos I, Saridomichelakis $M N$. First report of Neotrombicula autumnalis infestation in a cat and a dog from Corfu (Greece) and in a cat from Limassol (Cyprus). Vector Borne Zoonot Dis. 2012;12:1065-7.

10. Kampen H, Scholer A, Metzen M, Oehme R, Hartelt K, Kimmig P, et al. Neotrombicula autumnalis (Acari, Trombiculidae) as a vector for Borrelia burgdorferi sensu lato? Exp Appl Acarol. 2004;33:93-102.

11. Literak I, Stekolnikov AA, Sychra O, Dubska L, Taragelova V. Larvae of chigger mites Neotrombicula spp. (Acari: Trombiculidae) exhibited Borrelia but no Anaplasma infections: a field study including birds from the Czech Carpathians as hosts of chiggers. Exp Appl Acarol. 2008;44:307-14.

12. Fernandez-Soto P, Perez-Sanchez R, Encinas-Grandes A. Molecular detection of Ehrlichia phagocytophila genogroup organisms in larvae of Neotrombicula autumnalis (Acari: Trombiculidae) captured in Spain. J Parasitol. 2001;87:1482-3.

13. di Meo N, Quaranta L, Crisman G, Trevisan G. Adamantiades Behçet disease triggered by a tick bite and or borrelia infection. J Eur Acad Dermatol Venereol. 2009;23:1198-9.

14. Nasca MR, Lacarrubba F, Micali G. Diagnosis of trombiculosis by videodermatoscopy. Emerg Infect Dis. 2014;20:1059-60. 